University of Nebraska - Lincoln

DigitalCommons@University of Nebraska - Lincoln

Architectural Engineering -- Faculty Publications

Architectural Engineering and Construction,

Durham School of

$4-2012$

\title{
A Comparative Study of Three Feedback Devices for Residential Real-Time Energy Monitoring
}

\author{
Mahmoud Alahmad \\ University of Nebraska - Lincoln, malahmad2@unl.edu \\ Patrick G. Wheeler \\ University of Nebraska at Omaha, pwheeler@mail.unomaha.edu \\ Joshua Eiden \\ Alvine Engineering, jeiden@alvine.com \\ Adam Brumbaugh \\ University of Nebraska at Omaha, abrumbaugh@mail.unomaha.edu
}

Follow this and additional works at: https://digitalcommons.unl.edu/archengfacpub

Part of the Architectural Engineering Commons

Alahmad, Mahmoud; Wheeler, Patrick G.; Eiden, Joshua; and Brumbaugh, Adam, "A Comparative Study of Three Feedback Devices for Residential Real-Time Energy Monitoring" (2012). Architectural Engineering -Faculty Publications. 48.

https://digitalcommons.unl.edu/archengfacpub/48

This Article is brought to you for free and open access by the Architectural Engineering and Construction, Durham School of at DigitalCommons@University of Nebraska - Lincoln. It has been accepted for inclusion in Architectural Engineering -- Faculty Publications by an authorized administrator of DigitalCommons@University of Nebraska Lincoln. 


\title{
A Comparative Study of Three Feedback Devices for Residential Real-Time Energy Monitoring
}

\author{
Mahmoud A. Alahmad, Member, IEEE, Patrick G. Wheeler, Avery Schwer, Joshua Eiden, and Adam Brumbaugh
}

\begin{abstract}
Residential energy consumption accounts for $21 \%$ of the total electricity use in the United States. Unfortunately, research indicates that almost $41 \%$ of this power is wasted. Changing the way that consumers use energy may be important in reducing home energy consumption. This paper looks at whether the implementation of certain real-time energy monitors has an impact on the residential rate of energy consumption in a metropolitan area with relatively low electricity rates. In the following case study, 151 Omaha residences were equipped with two variants of the Aztech In-Home Display (Aztech) as well as the Blue Line Power Cost Monitor (PCM) real-time energy monitors for a period of 16 months. The results of the data, 30 days after installation, revealed a statistically insignificant reduction of $12 \%$ in mean electrical consumption in houses equipped with a PCM and no reduction in mean consumption in homes using either variants of the Aztech device when compared to a randomly selected control sample. However, they proved effective in the short term if utilized by utilities for mass distribution to foster awareness among participating residents of their own patterns of residential electricity consumption and on the environmental impacts of energy saving.
\end{abstract}

Index Terms-Energy conservation, energy consumption, energy management, energy measurement, real-time energy monitoring, residential power usage.

\section{INTRODUCTION}

A CCORDING TO the Energy Information Administration, "...the average American consumes six times the world average per capita consumption of energy." In fact, in just 2002 alone, the United States consumed 97.4 quadrillion BTU's, or more than twice that of any other developed nation in the world [1]. The 2010 Annual Energy Outlook records a 14\% increase in primary energy consumption in the U.S. from 2008 to 2035, or an average annual growth rate of $0.5 \%$. Furthermore, $\mathrm{CO}_{2}$ emissions are projected to increase by $0.3 \%$ per year within the same time frame. This increase is mostly derived from the

Manuscript received November 24, 2010; revised March 10, 2011 and June 12, 2011; accepted August 4, 2011. Date of publication August 18, 2011; date of current version November 1, 2011. This work was supported in part by Omaha Public Power District, Omaha, NE.

M. A. Alahmad, A. Schwer, and A. Brumbaugh are with the Durham School of Architectural Engineering and Construction, University of Nebraska-Lincoln, Peter Kiewit institute, Omaha, NE 68182 USA (e-mail: malahmad2@unl.edu; aschwer@mail.unomaha.edu; abrumbaugh@mail. unomaha.edu).

P. G. Wheeler is with the Environmental Health and Safety, University of Nebraska at Omaha, Omaha, NE 68182 USA (e-mail: pwheeler@mail. unomaha.edu).

J. Eiden is with the Alvine Engineering, Omaha, NE 68102-1814 USA (e-mail: jeiden@alvine.com).

Color versions of one or more of the figures in this paper are available online at http://ieeexplore.iee.org.

Digital Object Identifier 10.1109/TIE.2011.2165456 electric power and transportation sectors [2]. The electric power sector is experiencing a shift in its generation, transmission, and distribution system in an effort to reduce $\mathrm{CO}_{2}$ emissions, increase the use of renewable resources for a more energy sustainable future, and conserve precious resources through energy consumption. The distribution system in particular plays an important role in the built environment as an enabling product, an intangible necessity used to power our systems [3]. According to the United States Green Building Council, the built environment accounts for $72 \%$ of the total electricity consumption, $39 \%$ of energy use, $38 \%$ of all $\mathrm{CO}_{2}$ emissions, $40 \%$ of raw-material use, $30 \%$ of waste output (136 million tons annually), and $14 \%$ of potable water consumption in the U.S. [4].

U.S. homes also use approximately one-fifth of the total energy consumed in the nation with about $60 \%$ of that in the form of electricity. The residential sector, unlike the commercial and the industrial sector, is composed of multiple small energy users (houses, mobile homes, and apartments). Research shows that these small users waste almost $41 \%$ of their supplied power [5]. Such massive energy consumption and waste speak to the potential of the amount of energy that can be saved in the residential sector. In fact, one U.S.-based study has even put the value of deferring network upgrades at approximately $\$ 650 / \mathrm{kW}$ for the transmission network and $\$ 1050 / \mathrm{kW}$ for the distribution network [6].

In order to more efficiently reduce the amount of electricity waste in the residential sector, consumers need to change the types of behaviors that can lead to such waste [3]. Advanced metering initiatives (AMIs) are currently addressing multiple segments of such smart grid challenges. At the consumer side of the smart grid, i.e., within the residence itself, energy feedback and automation are gaining momentum as promising methods to motivate consumers to modify their energy consumption patterns [7]-[11].

Research and innovation in real-time energy monitoring have been steadily evolving for over the past 40 years. In [12], the vision of ambient intelligence for the built environment is presented, where data mining communications technology sensors, actuators, and power supplies, among others, are needed to accomplish behavior learning in dwelling environments. The authors in [13] propose an intelligent data analysis method for the automated classification of the energy consumption profile of a building. This is due to the fact that energy efficiency in buildings is of prime concern to identify energy saving. To collect building energy data, automated meter readings and smart metering systems are employed. Furthermore, to insure that energy is being used most efficiently, the paper discusses 
a comparison between consumers that is used to examine consumption habits. In [14], a wireless sensor and actuator network is discussed for building environment control system, where a centralized and a distributed control are used for energy efficiency opportunities. In [15], the importance of wireless sensor network for the smart grid is discussed along with challenges and opportunities. This is critical as the customer (residential, commercial, and industrial) is one of the main seven domains of the smart grid [16].

In June 2010, a comprehensive review of 57 of the most ground-breaking energy conservation projects since the 1970s was published by the American Council for an Energy-Efficient Economy (ACEEE) [7]. The first study employing real-time direct digital displays was conducted in 1992 [50]. The introduction of more aesthetically pleasing and intuitive device in later studies led to increased energy savings [51], [52]. The use of real-time feedback presents an opportunity to decrease residential energy consumption by $10 \%-20 \%$. The order of magnitude of the savings varies depending on the location of the study, the cost of power, and the type of feedback or information offered, as well as other socioeconomic factors. A synopsis of recent studies involving real-time monitoring (RTM) technology can be found in [17]-[31] and [53]-[58].

The RTM devices currently available on the market only monitor and display the overall energy consumption for the home and do not identify the ways in which individual residents consume energy. Users are thus responsible for both determining the location of wasted energy and taking the necessary actions to reduce that waste. This need has opened ample opportunities for research on creative methods that encourage more energy-efficient lifestyles.

The integration of energy aware and context aware methodologies led to demand response and demand side management, a proven energy-saving method for commercial and utility applications. This method is now starting to be implemented in the residential sector. The sensor network, now ubiquitously present throughout the U.S., is being integrated as an essential tool in future smart homes. The focus of current research is moving toward smart homes, home automation, and smart meters with demand response integration able to shut off loads by the utility during periods of high peak demand. This intrusive method does not provide for user comfort. However, when the user is empowered to make that decision, the results are tolerated and accepted, resulting in additional savings.

This paper addresses two key factors motivating this change: The use of real-time energy monitors to motivate users to change their consumption habits and the evaluation of current AMIs and their influence on energy conservation. Although the overall purpose of this and related projects is to find ways to help consumers lower their overall electricity usage, the critical time of use (or peak demand period) is of great concern. For this reason, it is critical to ascertain not only whether consumers saved electricity but also when and how that electricity was saved. This paper is organized as follows: Section II provides a history of the tools and monitoring equipment used in the energy conservation efforts. Section III gives a detailed description of the case study. Section IV is an analysis of the data and

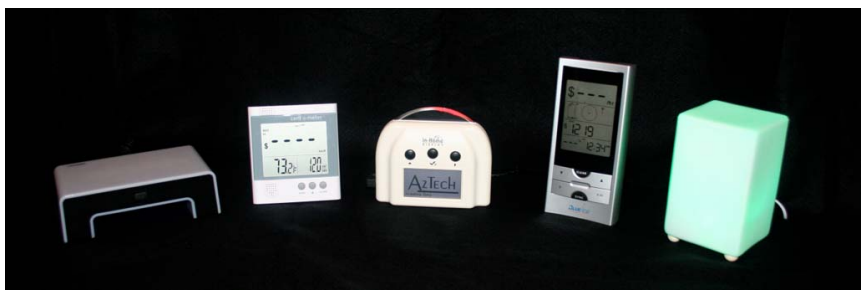

Fig. 1. In-home energy displays from left to right: Wattson, Cent-A-Meter, Aztech, PCM, and Ambient Orb.

summary of the results from the study surveys. The summary and conclusion are given in Section V.

\section{FEedBACK AND CONSERVATION}

\section{A. Early Energy Conservation Studies}

It was not until the 1970s that researchers became interested in studying the consumption behaviors of homeowners and renters. This desire to conserve energy was instigated by the energy crisis created by the 1973 Arab Oil Embargo. The primary investigators of some of the first studies were psychologists who were interested to know if providing consumers with feedback of their consumption behaviors could decrease electricity usage. Several studies that incorporated feedback in the form of notes left on doors or kitchen windows, meter reading, and self-monitoring are reviewed in [18]. These studies were among the first aimed at the residential sector and sought to help consumers better understand the cost of using electricity in hopes of minimizing their personal contribution to the power grid. A baseline usage was developed by monitoring homes for a period of time before starting the study. These studies, performed in the 1970s and 1980s, reported an energy savings between $7 \%$ and $30 \%$ [32]-[37]. The utility can control feedback through load management or through the use of smart meters to conserve energy. An energy tool that consumers can use is the home energy audit which allows them to see the areas where they could be more efficient. Such audits can be performed by the utility company, the homeowner, or a third party [21].

\section{B. RTM}

Real-time in-home feedback is a relatively new technology. A number of RTMs are now available that monitor home energy usage. These instruments allow users to input utility rate structures and receive feedback in the form of numerical and graphical data. Users are, for example, informed of their kilowatthour consumption and electricity costs. Fig. 1 shows some of the devices that will be described in more detail in the following sections.

1) Ambient Energy Orb (Orb): The Ambient Energy Orb [38] is an energy monitoring system that resembles a piece of modern art. A color changing LED is enclosed in a frosted glass casing to create a soothing ambient light. The Orb receives a signal from a paging network sent by the Ambient Information Network. The Ambient Network transmits signals that correlate with events such as the outdoor weather or the status of the 
stock market by the color of the Orb. The Ambient Network for monitoring electricity usage sends a signal to users based on the electric utility demand. It offers a visual cue of the utility electricity current demand to homeowners. The Orb is installed by the user by plugging it into any standard outlet. Once plugged in, little user interaction is necessary. The information provided is purely visual and does not alert occupants to any information pertaining to individual electricity usage. Like cell phone networks, the Ambient Network has regions where coverage may not be available to homeowners. It takes the network about $5 \mathrm{~s}$ to update the color change or pulsing effects. Energy Orbs were introduced in California residences for 10 months as part of the 2004 Southern California Information Pricing Pilot. Investigators examined whether the critical peak pricing information provided by the display lighting of the Energy Orb could encourage consumers on a time-varying rate plan to conserve energy. The 30 residential participants provided with feedback saved about $0.5-0.7 \mathrm{~kW}$. Overall, in terms of energy savings, however, these results were considered statistically insignificant [66].

2) Aztech In-Home Display (Aztech): The Aztech [34] is an intelligent RTM that interfaces with the new Itron digital electrical meter. The device offers a combination of visual and digital information. It can read the encoder-receiver-transmitter (ERT) radio signal from the electrical meter. Three menus offer a variety of numerical and graphical data recording the home's electricity usage, including a main view showing the current rate of consumption in kilowatts $(\mathrm{kW})$ and cost per hour of usage, a history view with bar graphs that displays energy usage within the past $24 \mathrm{~h}$ and past 30 days in kilowatthours and dollars, and a summary view that analyzes the total usage since the last time that the device was reset. The menu allows the user to select the reset day so that it coincides with the billing cycle. The visual display is in the form of a light bar that rotates across the top of the device so that it emulates the spinning of an analog electromechanical meter. The programming of the color-wheel changes and the outputs of the different menus are customizable through the manufacturer according to the utility or homeowner's specific needs. The device also offers feedback (often with a 2-4-min delay) and combines statistical, graphical, and visual data of the energy usage of the residence in question. The programming of the device can be modified via the manufacturer's Web site. As far as the author's knowledge, the study described herein is the first to specifically consider the impact of the Aztech device on residential home energy consumption rates.

3) Cent-A-Meter: The Cent-A-Meter [40] monitors home energy consumption at the electric panel by employing a wireless real-time electricity monitor. The liquid-crystal-display monitor is easy to read, displays the running cost, $\mathrm{W} / \mathrm{kW} / \mathrm{kWh}$, and the real-time power consumption, and updates every $12-60 \mathrm{~s}$. The display is portable and can be wall mounted or set on a counter within $30 \mathrm{~m}$ of the panel. An optional alarm beeps when the device determines that the residential rate of energy consumption is high. The device is installed in the residential electrical panel using current transmitters that are wired to the transmitter device (and requires the assistance of an expert). The display and transmitter units each require 4-AA batteries in order to operate. Presets return to the default mode when the batteries in the display are replaced/removed.

Currently, to the author's knowledge, there are no studies yet that directly test how the Cent-A-Meter might influence consumer behavior change and energy conservation practices. However, it has been analyzed as part of studies in the nontechnical literature. The Center for Sustainable Energy conducted a qualitative study that included the U.K. version of the CentA-Meter. Thirty-eight participants were divided according to age group and asked to keep a diary of their preferences and interaction with the selected home energy monitoring device. Diary entries were then analyzed in terms of how the design of the devices might be improved to better accommodate user needs and preferences [67].

4) EML 2020H: The EML 2020H [41] monitors the total home energy consumption through the use of current transformers (CTs). The display broadcasts information that it receives from the CTs to a personal computer in real time. The display must be installed near the electric panel. Since it is hardwired to the CTs, a qualified professional is needed to ensure safe installation. The display is easy to use, shows the running energy cost, $\mathrm{W} / \mathrm{kW} / \mathrm{kWh}$, and gives the per-second real-time energy consumption rate. While the device itself does not require batteries, the display must be plugged into an electrical outlet and hardwired to the panel in order to operate. Documentation of the use of the EML $2020 \mathrm{H}$ in household energy consumption initiatives is not yet available to the extent of the author's knowledge.

5) The Energy Detective (TED): The Energy Detective (TED) [42] monitors the total energy consumption throughout the home using CTs. It tracks the running cost, $\mathrm{W} / \mathrm{kW} / \mathrm{kWh}$, and the real-time power consumption rate for every $2-3 \mathrm{~s}$. TED Display is compact, making it convenient to plug into outlets in the kitchen, living room, or other high-traffic areas. As with the other devices, a qualified professional is needed for installation since the CTs must be placed into the residential electric panel. The CTs connect to a transmitter that sends the power usage information via the home wiring to the display unit. It is not battery operated and stores all data even when unplugged.

In a two-year study by the Florida Solar Energy Center, 17 south Florida homes conserved a daily average of $4.6 \mathrm{kWh}$ after implementation of TED. The researchers concluded that the device accurately provides measurements for loads greater than $10 \mathrm{~W}$ yet is not very effective in calculating small loads and loads with a low power factor [68]. TED was also tested in a three-month study of four low-income and six highincome residences in Oberlin, Ohio, to determine if the in-home presence of the device influenced occupant energy conservation behaviors. It was found that, although occupants reported increased awareness of their energy use from the interaction with the device, actual energy savings and changes in behavior were minimal [69].

6) PCM: The Power Cost Monitor (PCM) [43] is a device that displays the running cost, $\mathrm{W} / \mathrm{kW} / \mathrm{kWh}$, and the current time-of-use period and refreshes the real-time power consumption within $15 \mathrm{~s}$. The quick response time allows users to pinpoint the impact of individual energy usage such as microwaves and clothes dryers. The display does not utilize any 
color communication but does have a visual cue that simulates the spinning of an electromechanical meter. The device also consists of a transmitter unit in the form of a collar that goes directly on the electrical meter which reads the pulsing or rotation using an optical reader. A receiver unit can be placed anywhere within the home. Each component requires 2-AA batteries.

The effects of the PCM on home electricity consumption have been analyzed in other reports with the most notable and sizable of these involving a two-and-a-half-year study of 500 customers of the Hydro One Utility District in Toronto, Ontario. Study investigators found that implementing PCMs in homes could result in a $6.5 \%$ average aggregate reduction in household energy consumption. Participants also reported through a survey questionnaire a $60 \%$ satisfaction level with the usefulness and operation of the monitor [23].

7) Wattson: The Wattson [44] is a small and attractive monitoring device that displays energy usage by way of a color signal and digital display. The display illustrates the current kilowatts used in the home and gives a current cost. It also has a function that enables it to calculate the cost of electricity for an entire year based on the current rate of consumption. The device uses current transmitters that clip over the main phase conductors in the electrical panel. Although it only comes with one CT, additional CTs can be purchased to monitor multiple phases within the home. A qualified professional is required to install the CTs. The Wattson also requires batteries and a plug converter for the power cord to convert from the European standard.

Previous studies of the device have been primarily qualitative in nature as part of the nontechnical literature. Researchers installed the Wattson and Eco-Eye Elite energy monitoring devices in U.K. homes as part of a small-scale ethnography on occupant usage practices and the domestication of energy feedback devices. In-home interviews revealed that, while study occupants initially felt engaged by the immediacy of the feedback and the color changing visual effects of the Wattson, this interest declined over time. They conclude, in line with other studies, that feedback devices may not be adopted into household usage practices in the long term [63]. Another study specifically considered the impact of the design of the Wattson on consumer opinion, with participants finding the device annoying (due to flickering lights) and cumbersome (due to its size and short battery life). Even with these drawbacks, however, the Wattson was preferred among the other studied devices for its aesthetically pleasing design and ability to provide at-a-glance consumption "reference points" [64]. Moreover, in a recent and still on-going U.K.-based study, the Wattson device is utilized in conjunction with the social networking site Facebook to determine if peer influence and online social networks might promote energy conserving behaviors [65].

8) Other Devices/Tools: There are other devices and online tools on the market that also employ RTM technologies. Google PowerMeter is a tool that enables users to view energy consumption data from anywhere online [45]. ENVI, an RTM monitor that provides information on whole house energy usage, can gather data for up to nine individual appliances. These data are then displayed in Google's PowerMeter [46].
Microsoft's Hohm is a free Web-based beta application that provides information and recommendations on energy savings based on information submitted by project participants [47]. EnergyHub is another RTM that communicates with ZigBeeenabled utility smart meters and then sends this information to a touch-screen dashboard. With additional kits (strips and sockets), individual loads can be controlled and automated for shutoff [48]. TENDRIL Vision is a touch-screen display that provides current and historical household consumption data, neighborhood energy usage, time-of-use information, and demand response event support [49].

Various energy monitoring systems are also available outside of the U.S. The AlertMe Energy system, for example, is specifically configured to monitor energy use in the European system. It consists of CTs that connect the incoming electrical service and wirelessly send this information for online monitoring. AlertMe SmartPlugs can be added at individual outlets to control energy consumption to control the on/off operation [60]. Efergy, a global manufacturer of energy products, has developed a suite of products to monitor and control energy. These products include the wireless electricity monitor E2; the Elite Wireless Monitor, a system that updates energy consumption every $6 \mathrm{~s}$ to allow the resident to see the impact of their actions in terms of the energy usage; the Energy Monitoring Socket to measure the efficiency of home appliances; and the Remote Standby Eliminator that automatically shuts down appliances such as the entertainment system after use [61]. The Ewgeco, a product registered to Tayeco Ltd., provides RTM for gas, electricity, water, and renewable resources. It displays information using an easy-to-understand and engaging "traffic light" display design that rises and falls in real time. It gives information on the cost, kilowatts, liters/hour, and $\mathrm{CO} 2$ emissions [62].

\section{Omaha Residential Case Study}

ACEEE found that feedback devices alone are unlikely to maximize energy savings [7]. To the extent of the author's knowledge, this paper is the first large-scale comparative study of the Aztech and PCM devices that further confirms these findings.

The purpose of this case study is to thus investigate the effectiveness of the feedback methods of three devices on lowering residential consumption rates. Consumer response to the feedback and the specific device performance are also evaluated.

The various stages of the project required the following tasks: evaluation and selection of the RTM device(s), device installation, maintenance and feedback, device removal, and analysis of the results. The duration of the project was initially scheduled for the summer months with device removal intended for one year after installation. However, it was subsequently extended for an additional year to make the total duration of the project two years (January 2008 to June 2010). Project participants were given the option to opt out or remain in the study after the time extension. The following sections describe the case study in greater detail. 
TABLE I

Monitoring Device Evaluation CRITERia

\begin{tabular}{|l|c|c|c|c|c|c|c|}
\hline Device & $\begin{array}{l}\text { Insta- } \\
\text { llation }\end{array}$ & $\begin{array}{l}\text { Opera- } \\
\text { tion }\end{array}$ & $\begin{array}{l}\text { Aesthe- } \\
\text { tics }\end{array}$ & Accuracy & Bill & Interface & Total \\
\hline Orb & 1 & 5 & 1 & 5 & 1 & $7^{7}$ & 20 \\
\hline Aztech & 1 & 1 & 2 & $5^{1}$ & $10^{4}$ & 1 & 22 \\
\hline C-A-M & $8^{5}$ & 3 & 2 & $5^{1}$ & 5 & 2 & 25 \\
\hline Wattson & 6 & 4 & 3 & $5^{1}$ & $5^{8}$ & 2 & 25 \\
\hline EML & 10 & 5 & 5 & $5^{1}$ & $10^{4}$ & 3 & 38 \\
\hline PCM & 8 & $8^{2}$ & 2 & 10 & $10^{4}$ & 5 & 43 \\
\hline TED & 9 & $10^{3}$ & 4 & 4 & $10^{4}$ & $8^{6}$ & 45 \\
\hline
\end{tabular}

$1=$ Meets study goals; $10=$ Does not meet study goals;

Notes:

1) Unknown at this time, further study of device required

2) Special consideration for batteries required

3) Circuit breaker and display unit must be connected to the same phase

4) Displays running cost

5) Large CT's may not fit in some electrical panels

6) Too much information provided to the customer

7) Programming and monthly cost

8) Based on whether or not consumer has use of software

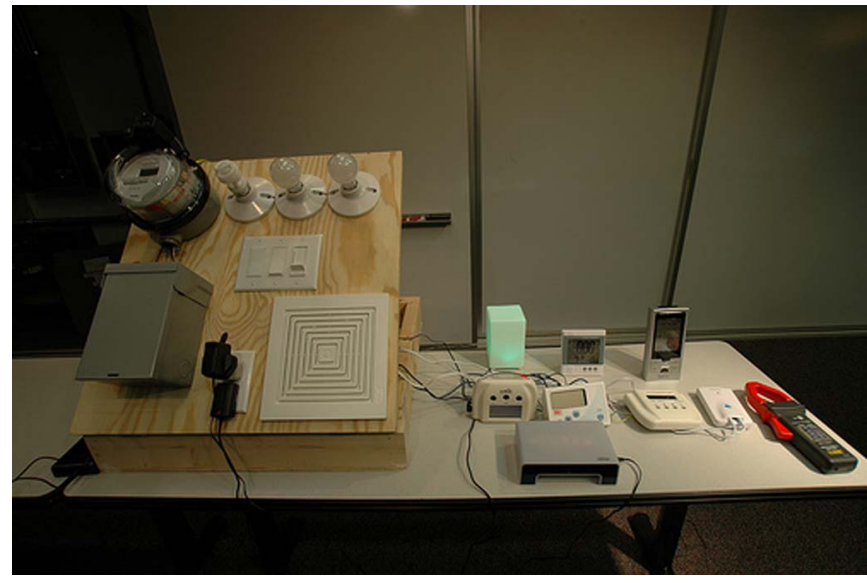

Fig. 2. Device testing using a simulated residential display board.

\section{A. RTM Evaluation and Selection}

The initial phase of the project sought to evaluate available devices at the time of the study and determine which device(s) was (were) most suited to the study goals. The previously described devices selected for analysis were the Ambient Energy Orb, the Aztech In-Home Display, the Cent-A-Meter (C-A-M in Table I), the Wattson, the EML 2020H, the PCM, and TED. As part of the preliminary evaluations, devices were tested using a customized prototype board designed to simulate the loads in a typical house as shown in Fig. 2. Each device was also installed in the personal residence of one of the project investigators to better evaluate its ease of installation, ease of use, and other more subjective considerations such as the relevancy of the data to the intended user group.

The devices were evaluated based on a predetermined set of criteria. Considered criteria included the complexity of the installation (some RTMs require CTs to be placed around the incoming service cables in the electrical panel, thus necessitating installation by a professional), maintenance require-

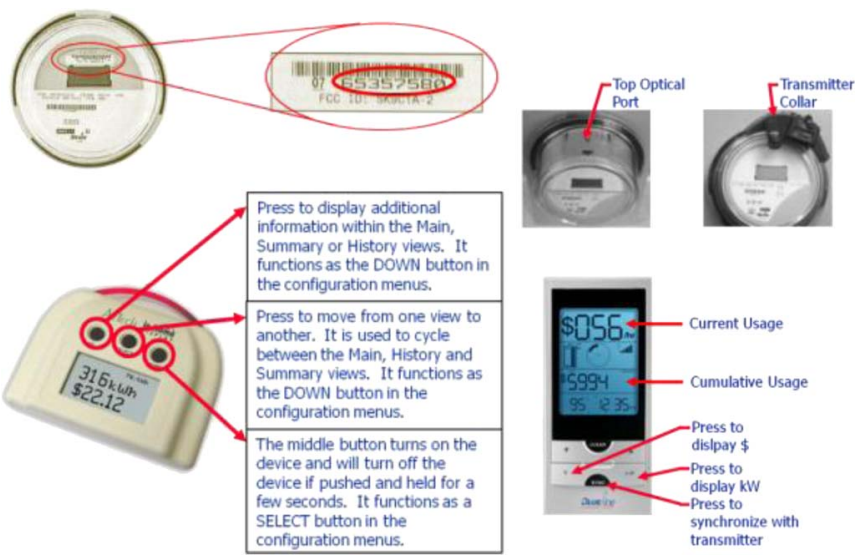

Fig. 3. RTM devices selected in this study.

ments (some RTMs require batteries that must be replaced at preset times), the signal distances between the transmitter at the electrical panel or utility meter and receiver [the display module must be located at a convenient location (i.e., kitchen table, living room, etc.)], recurring monthly costs associated with the network system requirements of some RTMs, and methods to convey consumption data using both visual cues and numerical data (digital and visual information), as well as other factors to include the ease of use, accuracy, and quality of data. Table I gives a summary of the criteria used to evaluate the device.

The Aztech In-Home Display was selected from the group of devices because of its ability to interact with the Itron electrical meter (once the Itron's unique ERT identification number is programmed into the device, real-time consumption data become available and are displayed), combine simple visual cues with digital feedback (color change and presentation method that emulates a spinning meter), integrate design with function (uses color change to reflect the utility's critical peak time or the user's percentage of the average kilowatthour daily consumption rate), and quantify data in the form of current power consumption, cumulative kilowatthours and cost, and graphical information based on the past $24 \mathrm{~h}$ and 30 days of energy usage. The Aztech In-Home Display was also chosen based on its ease of maintenance (requiring resetting only in the case of a power outage), its wireless operation, and the fact that usage entailed no recurring monthly costs.

Precision Data Systems offered 50 PCMs for inclusion in the study at no cost to the investigators. The PCM offers feedback similar to the Aztech but without the color changing effect. However, the design is still aesthetically pleasing: A rotating wheel simulates the spinning of a typical analog electrical meter that increases in speed as more energy is consumed. The PCM displays the current and cumulative energy consumption and cost data. Both monitors easily interface with the existing electrical utility meters. See Fig. 3 for a snapshot view and summary of how each device operates.

In order to compare how differing demand management feedback schemes might affect residential energy consumption rates, two separate customized colored light bar display patterns were developed and programmed for the Aztech devices and completed by the manufacturer at an additional cost of $\$ 3000$. 


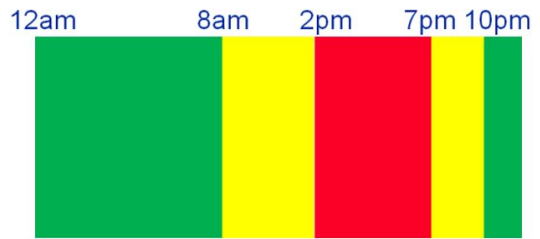

(a)

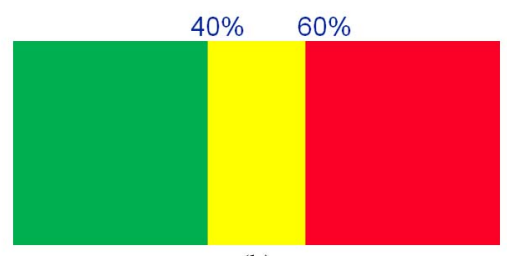

(b)

Fig. 4. Aztech device customization patterns. (a) AZI. (b)AZII.

The Aztech type I (AZI) is designed according to the traffic light color schema so that a green light bar emits color during periods of low demand, or typically from 10 P.M. to 7:59 A.M. This color changes to yellow from 8 A.M. to 1:59 P.M. and from 7 P.M. to 9:59 P.M. and to red from 2 P.M. to 6:59 P.M. when the utility demand is generally high. It was hypothesized that consumers interested in reducing costs might respond to this peak time-of-use information by engaging in energy saving behaviors during periods of higher demand. The Aztech Type II (AZII) light bar scheme, on the other hand, provides constant feedback of the historical electrical consumption information of a particular household. Colors change based on a comparison of the percentage of the average daily kilowatthour household consumption to that of the past three summers. Data from June to September of 2006 and 2007 were averaged to develop these daily summer kilowatthour usage data for each participant. The light bar resets to green at midnight each day and turns yellow when the daily cumulative energy consumption reaches $40 \%$ of the average daily usage from the previous summers. At $60 \%$, the color wheel changes to red. Fig. 4 gives a visual representation that shows when the color changes for each device occur.

Therefore, where one form of energy feedback encourages users to act according to the current demands of the utility, the other is designed in hopes that information on past usage patterns will motivate users to improve upon their current conservation behaviors.

\section{B. RTM Installation}

Study participants were self-selected by responding to a fourquestion survey sent to 2000 residential customers within the city limits of Omaha, Nebraska [59]. Homes were selected from a geographic area comprised of over 7000 homes that were already participating in an existing utility pilot study involving the wireless collection of electricity consumption data resolved to 15 -min intervals. In total, 214 respondents were willing to participate in the study. The project investigators contacted each chosen participant via phone or email and set up an appointment and home visit of approximately a half hour to install the device and explain its functionality. A Web site was also launched to address the questions or concerns of the participants and provide additional energy saving tips. Participants could also contact a dedicated university call center run by the research team to deal with any monitor-related issues. Out of the 214 initial respondents, a total of 151 homes participated in the study. In total, 50 AZIs, 50 AZIIs, and 51 PCMs were installed. Installations began in May 2008 and were completed by August 2008. In addition to the 151 participant homes, a control group of 95 homes (preselected by the utility) were included for purposes of comparison. These control homes were used by the utility for load forecasting on power consumption in the metropolitan area.

\section{Maintenance, Survey Distribution, and Device Removal}

Investigators performed follow-up visits to the participating homes in September of 2008 (during which a midterm survey was distributed) and in January of 2009 (to enter new electricity rates). Visits were also made during May of 2009 to ensure that the devices operated properly prior to the critical summer data collection period. During each visit, participants were given the opportunity to withdraw from participation in the study. The purpose of the survey was to collect the following information: user preferences (the specific features or attributes of a device that users find attractive), user involvement (the specific purposes of the device and the frequency with which it is used), motivation for change (user input on factors that motivated changes in energy consumption behaviors), and data on whether behavior change actually occurred. Data collection continued during the second summer of the study, and the devices were removed beginning in September 2009. A final survey was administered through the project Web site and via email after the removal of all the devices.

\section{Results}

\section{A. Data Analysis}

The residential energy consumption rates were evaluated to determine whether any electricity was saved 30 days after the initial installation of the devices. In order to determine the statistical significance, a factorial analysis of variance (ANOVA) was used. The analysis used random matching without replacement between the participants and the control group for two reasons: 1) The weather during the summer of 2008 was atypical when compared to the two previous summers, and 2) 82 of the home sales were uncertainties when trying to determine if the same resident had lived there for the past three years. Fig. 5 compares the electricity usage of all study participants against the control group. The evaluation revealed that the mean power consumed over the 30-day period immediately following the installation of either variants of the Aztech power monitoring device was higher than the amount of power consumed over the same 30-day period in houses in the randomly selected control group. The mean power consumption over the 30day period immediately following the installation of the PCM device was just under $12 \%$ less than the mean power consumed over the same 30-day period in houses in the randomly selected control group. This reduction was similar in magnitude to 


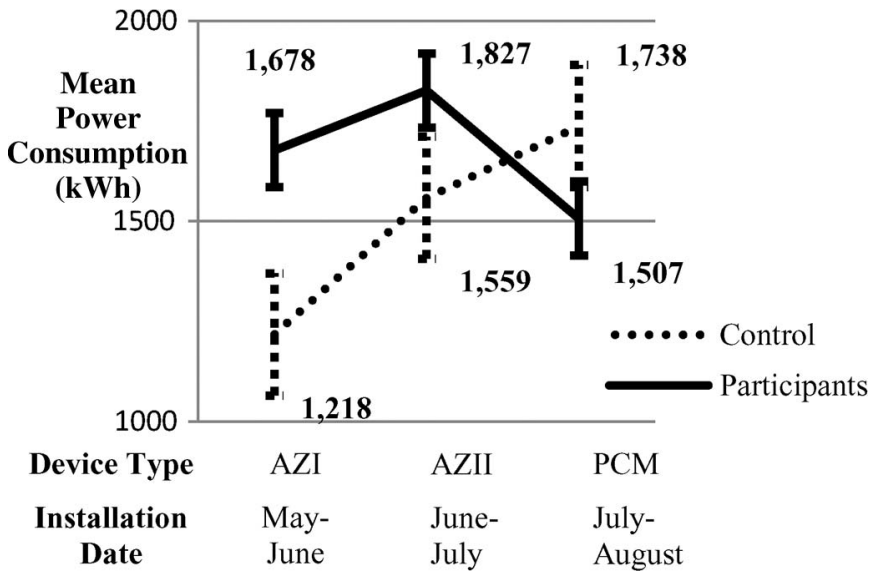

Fig. 5. Comparison of the electricity usage of the participants and control group during the first 30 days after device installation.

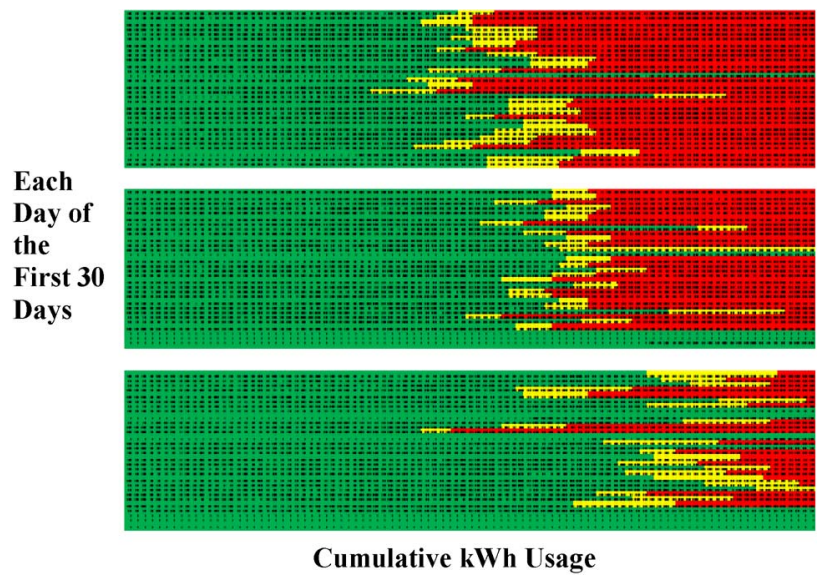

Fig. 6. AZII color change patterns for high, medium, and low energy consumption users.

the results reported by other investigators. Further statistical analysis comparing the mean power consumption in houses installed with the devices to the mean power consumption in houses in the randomly selected control group indicated that there was no statistically significant reduction in energy usage between the two groups $(t=0.6840, d f=92$, and $p=$ $0.2479)$. One of the reasons that might explain the difference in energy savings between participant groups using the Aztech and PCM devices is the differing device response times. The Aztech device requires a longer lag time to update current consumption rates. The PCM, on the other hand, updates in $30 \mathrm{~s}$ or less. As mentioned previously, some of the participants reported frustration with the feedback latency of the Aztech in the surveys.

Homes installed with the AZI or AZII were compared against the control group to determine whether the differing color prompting schemes created differing results in terms of the average per household kilowatthour energy consumption. Fig. 6 is a graphic representation of the energy consumption behavior of three study participants for each day of the first 30 days.

The average kilowatthour per 15-min interval for each type of color was compared. The mean values for the three color types are given in Table II.
TABLE II

Aztech Device Mean Kilowatthour Usage Per 15-Min InTERVal

\begin{tabular}{|l|c|c|c|}
\hline \multicolumn{4}{|c|}{ Display Color } \\
\hline Device Type & Green & Yellow & Red \\
\hline AZI & 0.45 & 0.56 & 0.69 \\
\hline Random Control & 0.37 & 0.42 & 0.53 \\
\hline AZII & 0.53 & 0.99 & 0.91 \\
\hline Random Control & 0.44 & 0.69 & 0.67 \\
\hline
\end{tabular}

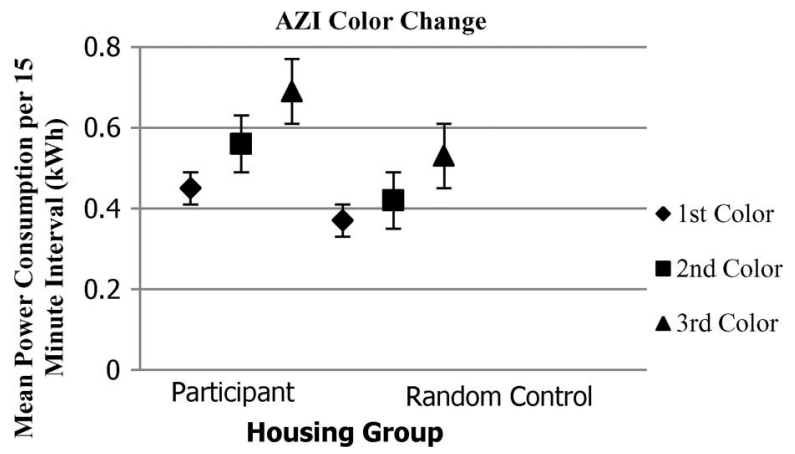

Fig. 7. Comparison using color change data for AZI.

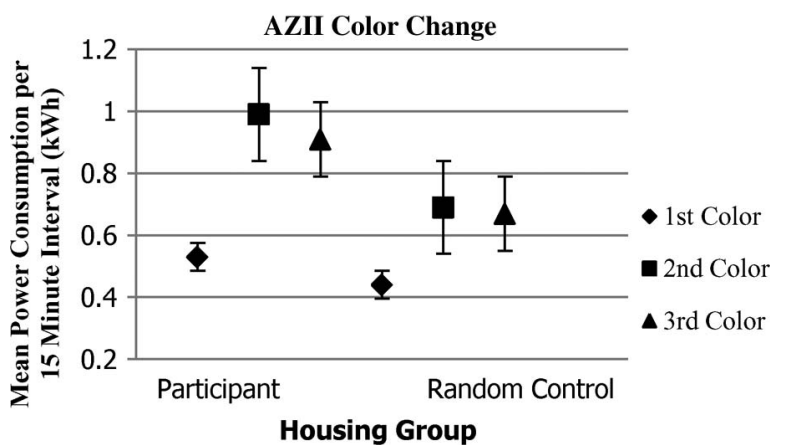

Fig. 8. Comparison using color change data for AZII.

Figs. 7 and 8 present a statistical comparison of the participant and the control group in terms of the color change of the AZI and AZII and the mean power consumption per 15-min interval (in kilowatthours), respectively. The data follow the same trend seen in the first 30 days of the analysis. Refer to Fig. 4 for the time color change patterns of each device type. Overall, the control group performed better than the participant groups with either variants of the Aztech device.

Peak usage occurred at different times in the day for different participants. Participants were grouped as low, medium, or high energy consumers. Figs. 9-14 show the consumption data collected on July 25, 2008, a typical summer day in Omaha, NE. The energy consumption data are given in kilowatthours per 15-min intervals for AZII, PCM, and the control group over a 24-h time period.

\section{B. Survey Analysis}

A nine-question survey was delivered by mail or hand, administered halfway through the RTM study and after the 


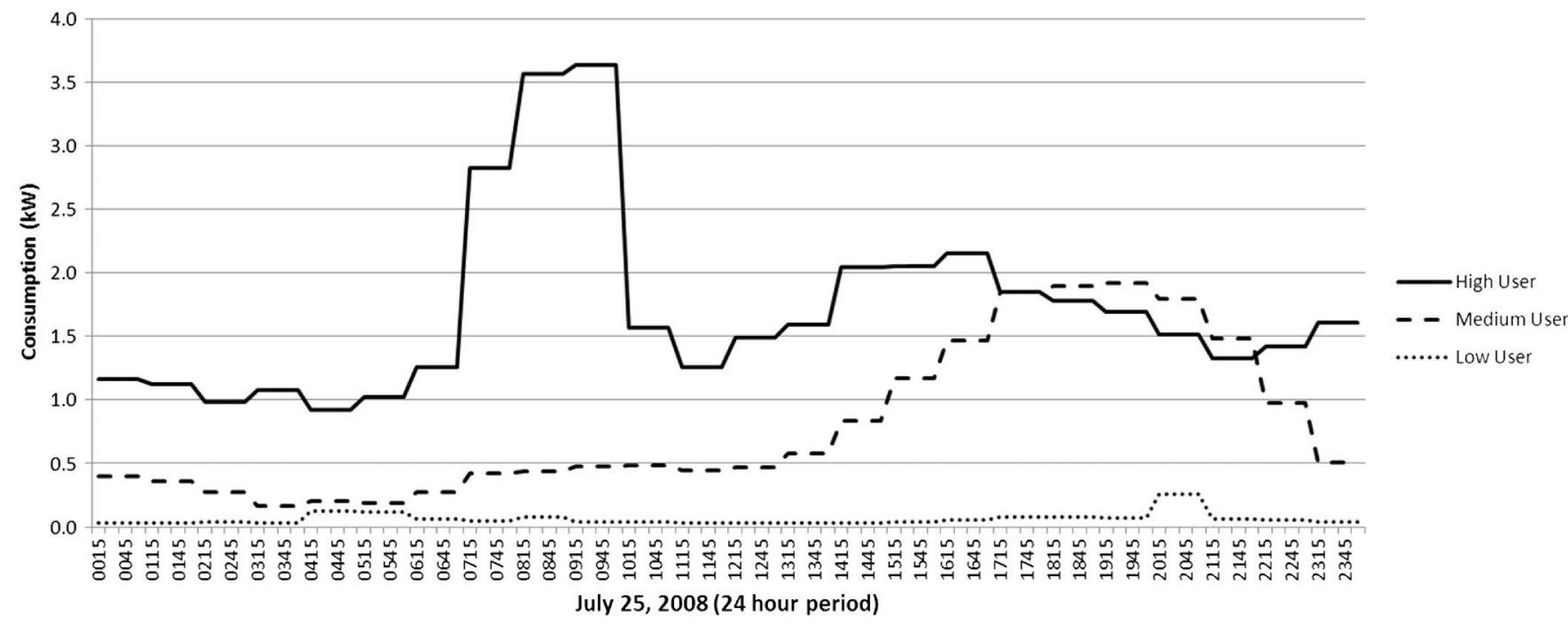

Fig. 9. Energy usage profile of a typical summer day (July 25, 2008) shows the high, medium, and low kilowatt consumption patterns of participants with Aztech monitors.

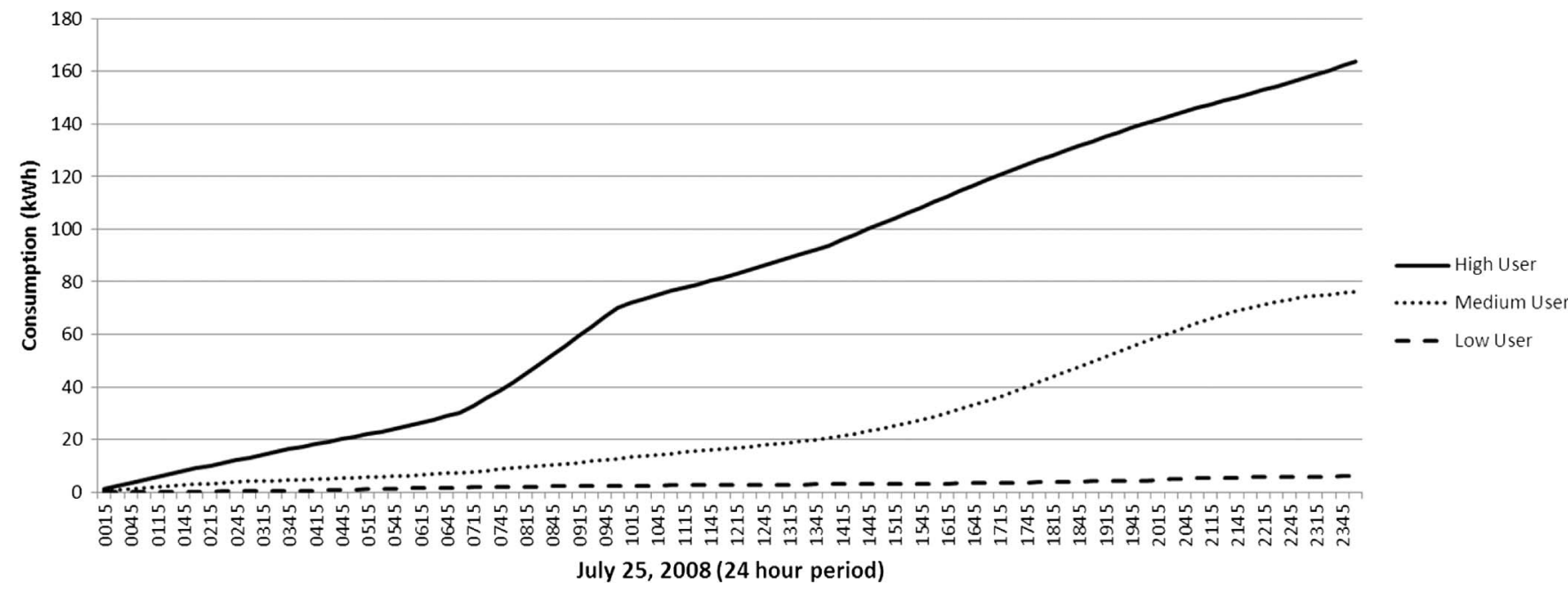

Fig. 10. Cumulative kilowatthour for participants with Aztech monitors.

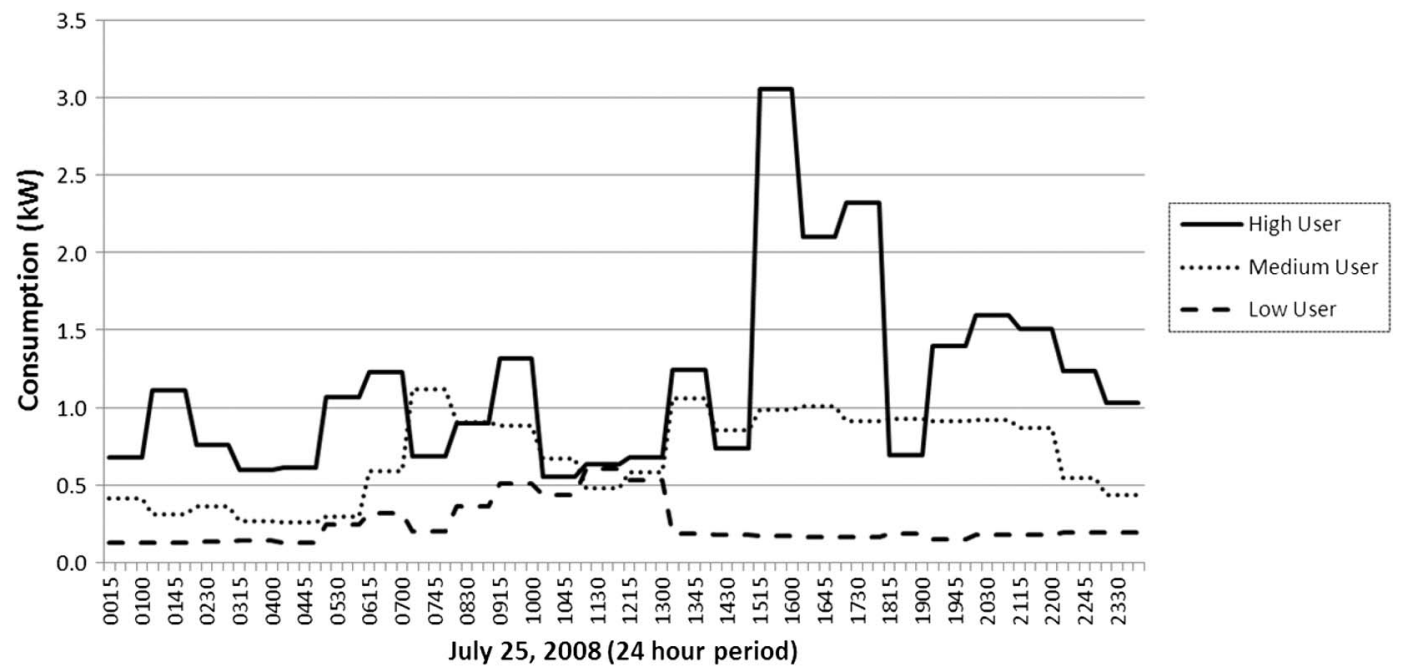

Fig. 11. Energy usage profile of a typical summer day (July 25, 2008) shows the high, medium, and low kilowatt consumption patterns of participants with PCM monitors. 


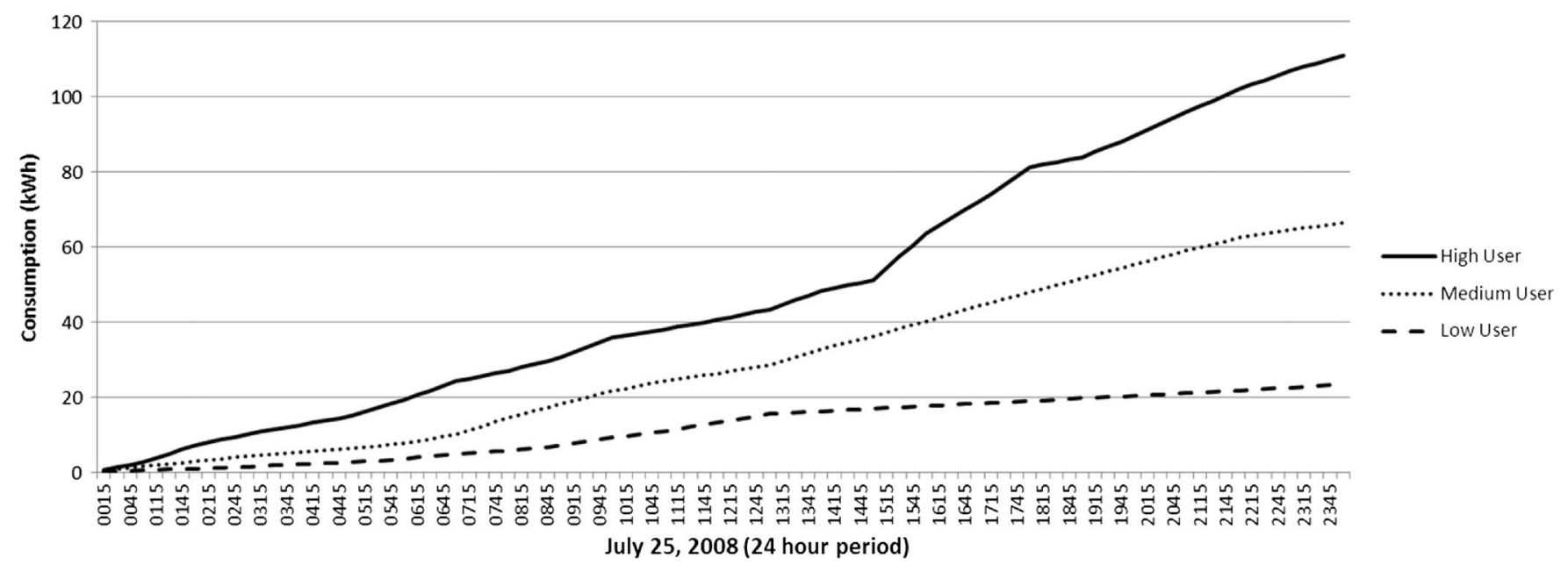

Fig. 12. Cumulative kilowatthour for participants with PCM monitors.

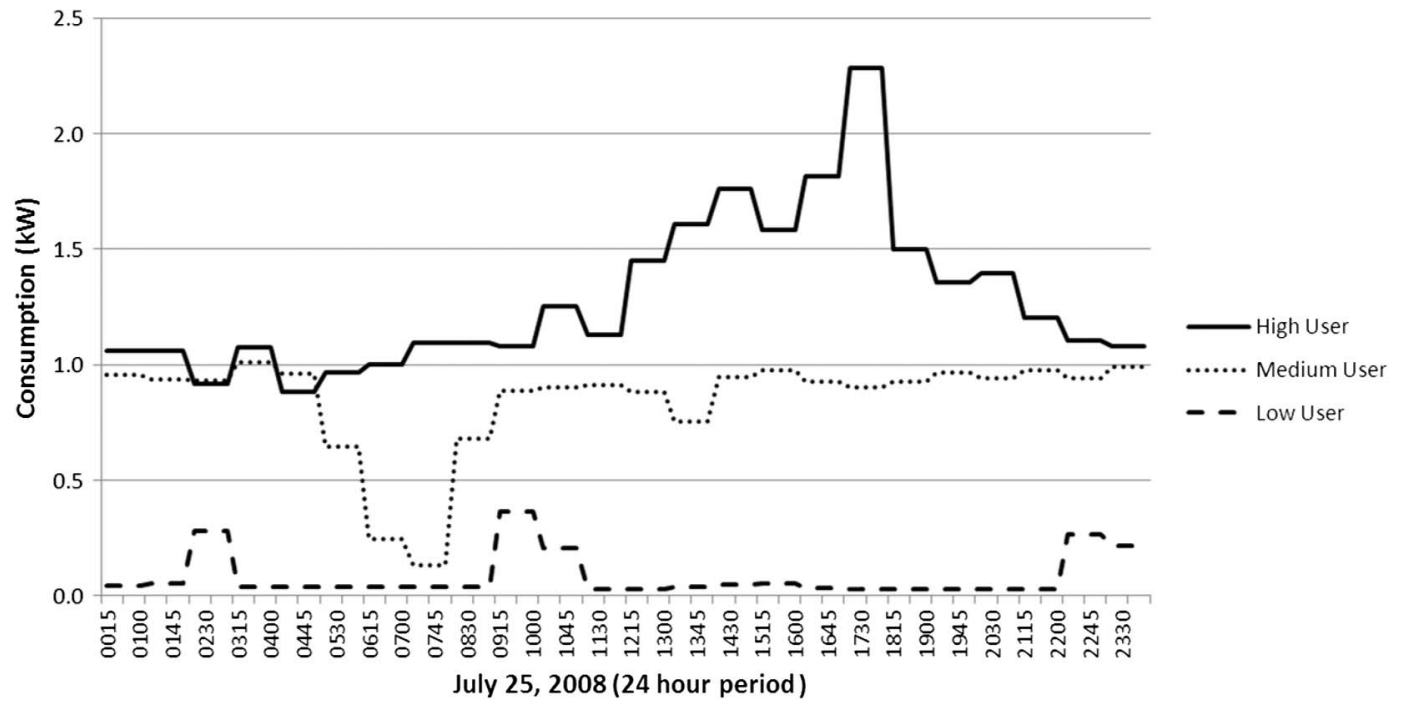

Fig. 13. Energy usage profile for a typical summer day (July 25, 2008) shows the high, medium, and low kilowatt consumption patterns of participants in the control group.

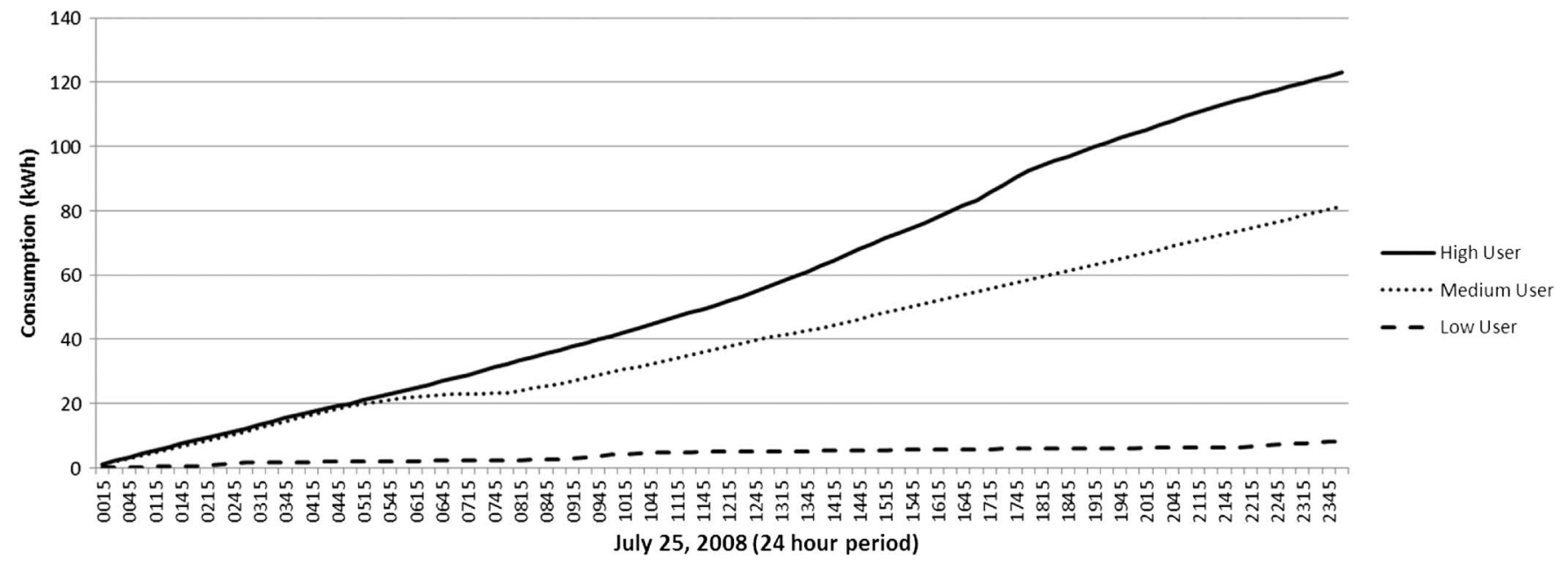

Fig. 14. Cumulative kilowatthour consumption for participants in the control group.

real-time monitors were uninstalled from the homes of the study participants. 100 surveys were completed at the midterm of the project period (29 AZI, 35 AZII, and 36 PCM), and
78 studies (23 AZI, 24 AZII, and 31 PCM) were submitted at the end. The approximate time span between each survey was 10 months. Although much of the data collected from the 
survey was subjective, the collected information gives insight into participant behavior that may be useful in creating future studies of this nature. In the survey, study participants indicated that they looked at the devices more often during the initial study period than at the end (16 midterm, 19 final). In line with the previous literature, it was inferred that, during the initial stages of the project, participants were also more interested in modifying their consumption behaviors. $10.5 \%$ of the participants said they did not look at the device as often as in the initial 30 days of the study.

Notably, not all the participants were satisfied with their energy monitors. Twenty of the respondents with the Aztech device claimed that the time delay of the response after loads were switched on is frustrating. The majority of the study participants generally believed that the device made them more conscious of their domestic energy use and thus modify their consumption patterns (67 midterm, 55 final). This is despite the fact that the actual power consumption data suggest otherwise.

Future energy reduction initiatives might target home televisions and computers. The average participant home had 3.56 televisions. $57 \%$ of the participants indicated that they leave their computers running all day, and $31 \%$ of the participants said that they had either a refrigerator, a stand-alone freezer, or both in their garage that consume a lot of energy during the summer months.

\section{Conclusion}

This paper has presented a case study of the electricity usage of 151 Omaha, Nebraska, residences to determine whether the feedback provided by real-time energy monitors results in lower residential consumption rates during the 30 days after installation. The study gave the real-time energy consumption in 15-min intervals. Direct feedback was provided via two surveys conducted during the course of and at the end of the study. The survey looked at whether the real-time monitors had any influence on participants' desire to conserve energy. Although the opinions of the project participants suggested that they took action to reduce their energy consumption as a result of the direct visibility of the real-time data, the actual power consumption data collected from the devices did not support such assertions. Furthermore, since the study participants selfselected themselves through contact with the university, it is likely that they already had an invested interest in energy conservation before the study began. Extending the study to include all Omaha homeowners would thus most likely create a very different outcome. While the results indicate that none of the feedback methods provided by the devices reduced the rate of energy consumption by a statistically significant amount in comparison to the control groups, previous research has shown that feedback can be useful for short-term energy saving. The survey results support this notion, as participants reported greater interaction with the device during the beginning of the study. Since all of the feedback methods depended on the energy saving behaviors of the participants in order for energy savings to occur (reducing loads required manual switching), this study supports the need for more innovative ways to reduce residential energy consumption than the studied devices and other feedback devices like them currently available on the market. Finally, the investigators also feel that the information on participant behavior acquired during the course of the project may have implications in the design of future studies.

In summary, the following are identified as outcomes of this work for other researchers in this field: The self-selected participants, who are interested in saving energy, may have taken actions to do so before the study began - this is based on information received from the participants in the surveys; the latency of real-time data is a major factor in impulse behavior to take action; participant interaction/frustration with the device during outages or battery replacements to reprogram it is critical to the continuing engagement and use of the device to save energy; devices are useful for short time period in the range of days and weeks not months and years; RTM availability in the market and differences of each as an incentive to save energy; the need to focus on one device only given the small sample of participants; and customization of the device to each user's own energy as a direct incentive to save.

\section{ACKNOWLEDGMENT}

The authors would like to thank the Omaha Public Power District staff for their support and collaboration. The authors would also like to thank Dr. D. Tiller for his contribution to the research project and assistance in developing this manuscript.

\section{REFERENCES}

[1] U.S. Energy Inf. Admin., Annual Energy Review 2006. Tables 1.3, 2.1b-2.1f, and 10.3.

[2] U.S. Energy Inf. Admin., Annual Energy Outlook 2010, last accessed Aug. 10, 2011. [Online]. Available: http://www.eia.doe.gov/oiaf/aeo/pdf/ 0383(2010).pdf

[3] E. Carroll, E. Hatton and M. Brown, "Residential Energy Use Behavior Change Pilot," CMFS project code B21383, Apr. 20, 2009, Franklin Energy.

[4] USGBC, Green Building Facts. last accessed Aug. 10, 2011. [Online] Available: www.usgbc.org/ShowFile.aspx?DocumentID $=5961$

[5] E. D. Williams and H. S. Matthews, "Scoping the potential of monitoring and control technologies to reduce energy use in homes," in Proc. IEEE Int. Symp. Electron. Environ., May 2007, pp. 239-244.

[6] K. J. Dyke, N. Schofield, and M. Barnes, "The impact of transport electrification on electrical networks," IEEE Trans. Ind. Electron., vol. 57, no. 12, pp. 3917-3926, Dec. 2010.

[7] K. Ehrhardt-Martinez, K. A. Donnelly, and J. A. Laitner, "Advanced metering initiatives and residential feedback programs: A meta-review of household electricity-saving opportunities," Amer. Council EnergyEfficient Econ., Washington, DC, Rep. E105, Jun. 2010.

[8] Y. Suhara, T. Nakabe, G. Mine, and H. Nishi, "Distributed demand side management system for home energy management," in Proc. 36th IEEE IECON, Glendale, AZ, Nov. 7-10, 2010, pp. 2430-2435.

[9] Y. Kamiyoshi, T. Nakabe, G. Mine, and H. Nishi, "Construction of energy measuring system in a University for Cluster Energy Management System," in Proc. 36th IEEE IECON, Distributed Demand Side Management System for Home Energy Management, Glendale, AZ, Nov. 7-10, 2010, pp. 2423-2429.

[10] M. Brychta, F. Dubisch, F. Stift, and P. Palensky, "QUEEN—A nove design flow and decision support tool for sustainable buildings," in Proc. 36th IEEE IECON, Glendale, AZ, Nov. 7-10, 2010, pp. 2448-2453.

[11] A. A. Zaidi, F. Kupzog, T. Zia, and P. Palensky, "Load recognition for automated demand response in microgrids," in Proc. 36th IEEE IECON, Glendale, AZ, Nov. 7-10, 2010, pp. 2442-2447.

[12] D. Bruckner and R. Velik, "Behavior learning in dwelling environments with hidden Markov models," IEEE Trans. Ind. Electron., vol. 57, no. 11, pp. 3653-3660, Nov. 2010. 
[13] X. Li, C. P. Bowers, and T. Schnier, "Classification of energy consumption in buildings with outlier detection," IEEE Trans. Ind. Electron., vol. 57, no. 11, pp. 3639-3644, Nov. 2010.

[14] X. Cao, J. Chen, Y. Xiao, and Y. Sun, "Building-environment control with wireless sensor and actuator networks: Centralized versus distributed," IEEE Trans. Ind. Electron., vol. 57, no. 11, pp. 3596-3605, Nov. 2010.

[15] V. C. Gungor, B. Lu, and G. P. Hancke, "Opportunities and challenges of wireless sensor networks in Smart Grid," IEEE Trans. Ind. Electron., vol. 57, no. 10, pp. 3557-3564, Oct. 2010.

[16] IEEE Smart Grid, Smart Grid Conceptual Framework. last accessed Aug. 10, 2011. [Online]. Available: http://smartgrid.ieee.org/smart-gridframework-diagram

[17] W. Abrahamse, L. Steg, C. Vlek, and T. Rothengatter, "A review of intervention studies aimed at household energy conservation," J. Environ. Psychol., vol. 25, no. 3, pp. 273-291, Sep. 2005.

[18] B. C. Farhar and C. Fitzpatrick, Effects of Feedback on Residential Electricity Consumption: A Literature Review, Solar Energy Res. Inst.,

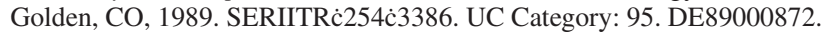

[19] CEATI, Results of Two-Year Study Demonstrates Residential Electricity Monitors Help Homeowners Conserve Electricity in a Big Way, 2008. last accessed Aug. 10, 2011. [Online]. Available: http://www. bluelineinnovations.com/documents/pr-ceati.pdf

[20] A. Faruqui, S. Sergici, and A. Sharif, "The impact of informational feedback on energy consumption," Energy, vol. 35, no. 4, pp. 1598-1608, Apr. 2010

[21] S. Darby, The Effectiveness of Feedback on Energy Consumption: A Review for DEFRA of the Literature on Metering, Billing and Direct Displays. Oxford, U.K.: Environ. Change Inst., 2006.

[22] G. Brandon and A. Lewis, "Reducing household energy consumption: A qualitative and quantitative field study," J. Environ. Psychol., vol. 19, no. 1 , pp. 75-85, Mar. 1999.

[23] Hydro One, Summary-The Impact of Real-Time Feedback on Residential Electricity Consumption: The Hydro-One Pilot, 2006.

[24] I. Matsukawa, "The effects of information on residential demand for electricity," Energy J., vol. 25, no. 1, pp. 1-17, Jan. 2004.

[25] G. R. Newsham and D. K. Tiller, "The energy consumption of desktop computers: Measurement and savings potential," IEEE Trans. Ind. Appl., vol. 30, no. 4, pp. 1065-1072, Jul./Aug. 1994.

[26] G. R. Newsham and J. A. Veitch, "Energy-efficient lighting options: Predicted savings and occupant impressions of lighting quality," in Proc. Clima, Brussels, Belgium, 2000.

[27] M. Grunwald, "Wasting our watts: We don't need new drilling or new power plants, we need to get efficient," Time, vol. 173, no. 1, pp. 32-36, 2000.

[28] D. S. Parker, D. Hoak, and J. Cummings, "Pilot evaluation of energy savings from residential energy demand feedback devices," Florida Solar Energy Center, Cocoa, FL, FSEC-CR-1742-08, 2008.

[29] B. Parks, "Home energy dashboards," Make: Technology on your own time, vol. 18 , pp. 48-51, 2009

[30] K. Roth and J. Brodrick, "Emerging technologies: Home energy displays," ASHRAE J., vol. 50, no. 7, pp. 136-138, Jul. 2008.

[31] T. Ueno, F. Sano, O. Saeki, and K. Tsuji, "Effectiveness of an energyconsumption information system on energy savings in residential houses based on monitored data," Appl. Energy, vol. 83, no. 2, pp. 166-183, 2006.

[32] C. Seligman and J. M. Darley, "Feedback as a means of decreasing residential energy consumption," J. Appl. Psychol., vol. 62, no. 4, pp. 363368, Aug. 1976.

[33] R. A. Winett and M. T. Nietzel, "Behavioral ecology: Contingency management of consumer energy use," Amer. J. Commun. Psychol., vol. 3, no. 2, pp. 123-133, Jun. 1975.

[34] R. A. Winett, J. H. Kagel, R. C. Battalio, and R. C. Winkler, "Effects of monetary rebates, feedback, and information on residential electricity conservation," J. Appl. Psychol., vol. 63, no. 1, pp. 73-80, Feb. 1978.

[35] R. G. Bittle, R. Balesano, and G. Thaler, "The effects of daily cost feedback on residential electricity consumption," Behav. Mod., vol. 3, pp. 187-201, 1979.

[36] R. A. Winett, M. S. Neale, and C. Grier, "Effects of self-monitoring and feedback on electricity consumption," J. Appl. Behav. Anal., vol. 12, no. 2, pp. 173-184, 1982.

[37] J. H. Van Houwelingen and W. F. Van Raaij, "The effect of goal-setting and daily electronic feedback on in-home energy use," J. Consum. Res., vol. 16, no. 1, pp. 98-105, Jun. 1989.

[38] Ambient Energy Orb, Ambientdevices. last accessed Aug. 10, 2011. [Online]. Available: http://www.ambientdevices.com/cat/index.html

[39] Aztech Assoc. Inc. last accessed Aug. 10, 2011. [Online]. Available: http://www.aztechinc.com/en/
[40] Cent-A-Meter. last accessed Aug. 10, 2011. [Online]. Available: http://www.centameter.co.nz/

[41] $E M L$ 2020H. last accessed Aug. 10, 2011. [Online]. Available: http://www.powermeterstore.com

[42] The Energy Detective. last accessed Aug. 10, 2011. [Online]. Available: http://www.theenergydetective.com/

[43] Blueline Innovations. last accessed Aug. 10, 2011. [Online]. Available: http://www.bluelineinnovations.com

[44] Wattson Device. last accessed Aug. 10, 2011. [Online]. Available: http://www.diykyoto.com/uk

[45] Google PowerMeter. last accessed Aug. 10, 2011. [Online]. Available: http://www.google.com/powermeter/about/about.html

[46] PowerSave Home Energy Monitor, ENVI. last accessed Aug. 10, 2011. [Online]. Available: http://www.currentcost.net/

[47] Microsoft HOHM. last accessed Aug. 10, 2011. [Online]. Available: http://www.microsoft.com/environment/hohm.aspx

[48] EnergyHub. last accessed Aug. 10, 2011. [Online]. Available: http://www.energyhub.com/

[49] TENDRILINE VISION. last accessed Aug. 10, 2011. [Online]. Available: http://www.tendrilinc.com/products/vision/

[50] J. K. Dobson and J. D. A. Griffin, "Conservation effect of immediate electricity cost feedback on residential consumption behavior," in Proc. Amer. Council Energy-Efficient Econ., 1992, pp. 10.33-10.35.

[51] K. Tanabe, "Energy conservation results of the survey project on the status of energy saving in the residential sector," presented at the IEA Presentation Standby Electricity, Tokyo, Japan, 2000.

[52] I. Mansouri and M. Newborough, "Dynamics of energy use in the UK households: End-use monitoring of electric cookers," in Proc. Eur. Council Energy-Efficient Econ., Mandelieu, France, 1999.

[53] Current Cost; Energy Monitors for Every Home. [Online]. Available: http://www . currentcost.com/download/CurrentCost-PressRelease_Monitors_for_Every_Home.pdf

[54] TXU Energy Power Monitor, 2008. last accessed Aug. 10, 2011. [Online]. Available: http://www.txu.com/en/residential/promotions/dsm/ /media/ Files/Marketing/DSM/PDFs/Power_Monitor1000_User_Guide.ashx

[55] D. Botkins, Dominion Virginia Power, Dominion Virginia Power Launches First of Nine Energy Conservation Pilots, 2008. last accessed Aug. 10, 2011. [Online]. Available: http://www.dom.com

[56] NSTAR, 2007. Residential Energy Efficiency Department. last accessed Aug. 10, 2011. [Online]. Available: http://www.nstaronline.com/ss3/ nstar_news/press_releases/2007/blueline.asp

[57] W. G. Jackson, Jr., Paragon Consulting Services Inc., A Review of Equipment Home Energy Display Devices "Description, Application and Issues, " 2008. NV Energy.

[58] Nexus Energy Software, Opinion Dynamics Corporation, Primen, and Southern California Edison, Information display pilot: California statewide pricing pilot, Rosemead, CA, Jan. 5, 2005. Final Rep.

[59] M. Alahmad, A. Wilkerson, and J. Eiden, "Collaboration with industry to promote energy conservation and education," in Proc. Annu. ASEE, Austin, TX, Jun. 14-17, 2009.

[60] AlertMe Energy Monitoring System. last accessed Aug. 10, 2011. [Online]. Available: http://www.alertme.com/products

[61] Efergy Products. last accessed Aug. 10, 2011. [Online]. Available: http://www.efergy.com/categories/efergy-Shop/cid-CK00000754.aspx

[62] Ewgeco. last accessed Mar. 6, 2011. [Online]. Available: http://www. ewgeco.com/products.htm

[63] C. F. Kelsey and V. M. Gonzalez, "Understanding the use and adoption of home energy meters," Proc. 4th Latin Amer. Conf. Human-Comput. Interact., Merida, Mexico, 2009.

[64] G. Fitzpatrick and G. Smith, "Technology-enabled feedback on domestic energy consumption: Articulating a set of design concerns," Pervasive Comput., vol. 8, no. 1, pp. 37-44, Jan.-Mar. 2009.

[65] D. Foster, M. Blythe, P. Cairns, and S. Lawson, "Competitive carbon counting: Can social networking sites make saving energy more enjoyable?" in Proc. CHI, Atlanta, GA, Apr. 10-15, 2010, p. 4039-4044.

[66] M. S. Martinez and C. Williamson, "California information display pilot (Energy Orb) evaluation: What effect does enhanced information have on critical peak price response?" in Proc. Energy Program Eval. Conf., New York, 2005, p. 337.

[67] W. Anderson and V. White, "Exploring consumer preferences for home energy display functionality," Center Sustain. Energy, 2009. Tech. Rep.

[68] D. Parker, D. Hoak, A. Meier, and R. Brown, "How much energy are we using? Potential of residential energy demand feedback devices," Florida Solar Energy Center/Univ. Central Florida, Cocoa, FL, 2008.

[69] D. Allen and K. Janda, "The effects of household characteristics and energy use consciousness on the effectiveness of real-time energy use 
feedback: A pilot study," in Proc. ACEEE Summer Study Energy Efficiency Buildings, Pacific Grove, CA, 2006.

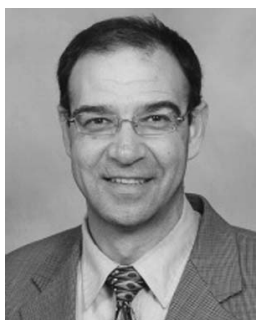

Mahmoud A. Alahmad (M'08) received the B.S. degree in electrical engineering, the M.S. degree in electrical engineering, and the Ph.D. degree in electrical engineering from the University of Idaho, Moscow, in 1989, 1991, and 2005, respectively.

$\mathrm{He}$ is currently an Assistant Professor with the Durham School of Architectural Engineering And Construction, University of Nebraska-Lincoln, Omaha. His research interests include real-time power monitoring in the built environment, battery power management, and renewable energy alternatives. Previous publications include several papers in the area of power management and microbattery testing and system design implementation. Industry experience includes electrical distribution system infrastructure planning and design for new and renovated facilities.

Dr. Alahmad has held Professional Engineering licensure since 1996. He is a peer reviewer for several journals and conferences, including the IEEE TRANSACTIONS ON INDUSTRIAL ELECTRONICS.

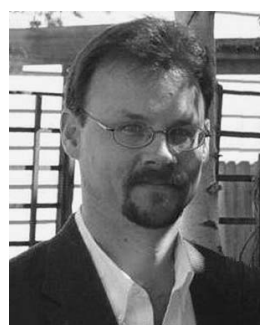

Patrick G. Wheeler received the B.S. degree in liberal arts, with specializations in sociology and nuclear technology, from Regents College, Albany, NY, in 1995, and the Master of Public Administration from the University of Nebraska at Omaha (UNO), Omaha, in 2001.

$\mathrm{He}$ is currently an Environmental Advocate at UNO and is a Ph.D. student in University of Nebraska-Lincoln (UNL)'s unified engineering program, with specialization in construction. He has over 25 years of experience in nuclear power, nuclear weapons, and hazardous material management. His interests in sustainability, energy policy, transportation energy, and public health have led him to help others learn about, and formulate solutions to, the complex problems that we face today. His position at UNO affords him the opportunity to work with (and to become familiar with expertise and interests of) faculty, staff, and students across the university. A systems thinker, Wheeler uses this knowledge and his own experience to facilitate creative solutions to elusive problems. His Ph.D. research focus is on the indoor air quality impacts of our built environment.

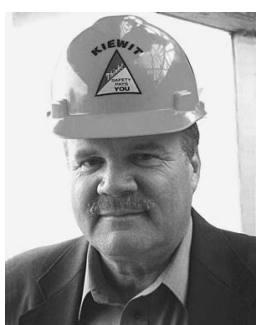

Avery Schwer received the B.S. in engineering technology and the M.A. degree in teaching education from the University of Wisconsin, Milwaukee, in 1974 and 1978, respectively, and the Ph.D. degree in administration from the University of NebraskaLincoln, Omaha, in 2001.

$\mathrm{He}$ is currently a UNL College of Engineering Professor with the Durham School of Architectural Engineering and Construction, University of Nebraska-Lincoln. He is the Director of the zero net energy test home (ZNETH) project which is a net zero test house next to the campus. He teaches the sustainable construction courses and is developing an online program in sustainable design and construction. His research focuses on the investigation of renewable and highperformance building applications.

Mr. Schwer serves on the Board of Directors for the United States Green Building Council Nebraska Chapter, and he has been recognized for service by Habitat for Humanity and United Way. Twelve of his student's research projects and course papers have won national and regional awards. He has earned the University of Nebraska Award for Distinguished Teaching.

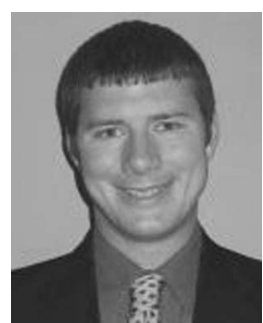

Joshua Eiden received the B.S. and M.A.E. degrees in architectural engineering from the Durham School of Architectural Engineering and Construction, University of Nebraska-Lincoln, Omaha.

$\mathrm{He}$ is currently an Electrical Engineer (EIT) with Alvine Engineering, Omaha. His M.A.E. research was based on real-time energy monitors.

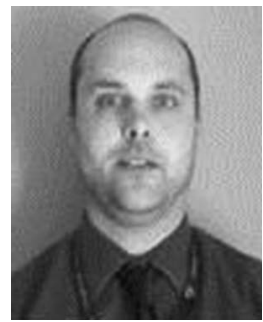

Adam Brumbaugh received the B.S. degree from University of Nebraska at Omaha, Omaha. He is currently working toward the M.A.E. degree in architectural engineering in the Durham School of Architectural Engineering and Construction at the University of Nebraska-Lincoln.

$\mathrm{He}$ is currently working at a major design firm for his internship. He has over 13 years of experience in the electrical design field and 4 years of experience doing research under the faculty in Omaha. He has been involved with several projects dealing with conservation and renewable energy sources. His research interests include arcfault calculations, selective coordination, and the effects that each has on arcflash ratings in electrical distribution systems. 